\title{
Shengmai Suppressed Vascular Tension in Umbilical Arteries and Veins of Human and Sheep
}

\author{
Xiaohui Yin"1, Xiuxia Gu1\#, Yun He1, Di Zhu1', Jie Chen11, Jue Wu1, Xueqin Feng1, \\ Jinhao Li ${ }^{1}$, Caiping Mao' ${ }^{1}$ Zhice $\mathrm{Xu}^{1,2^{*}}$ \\ ${ }^{1}$ Institute for Fetology \& Reproductive Medicine Center, First Hospital of Soochow University, Suzhou, China \\ ${ }^{2}$ Center for Prenatal Biology, Loma Linda University, Loma Linda, CA, USA \\ Email: ${ }^{*}$ xuzhice@suda.edu.cn, zxu@llu.edu
}

Received 13 May 2015; accepted 27 June 2015; published 30 June 2015

Copyright (C) 2015 by authors and Scientific Research Publishing Inc.

This work is licensed under the Creative Commons Attribution International License (CC BY).

http://creativecommons.org/licenses/by/4.0/

c) (i) Open Access

\begin{abstract}
Objective-The umbilical cord is a critical pathway between mothers and fetuses, and regulations of umbilical vessel tension are important for fetal growth. Shengmai is an herbal medicine being used in treatments of cardiovascular diseases. However, effects of Shengmai on human blood vessels and related pharmacological mechanisms are unclear. Methods-This study investigated the effects of related mechanisms of Shengmai and its key compounds on human and sheep umbilical arteries and veins using organ bath systems. Key Findings-Shengmai significantly suppressed phenylephrine-stimulated vasoconstriction in umbilical arteries and veins. NG-Nitro-L-arginine Methyl Estercould not change the Shengmai-suppressed vasoconstriction in human and sheep umbilical vessels. Among four key compounds of Shengmai, Ginsenoside Re, Ginsenoside Rb1, Ginsenoside Rg1, and Schisandrin, only Ginsenoside Re showed the significant effect similar to Shengmai's in the umbilical vessels. In $\mathrm{Ca}^{2+}$-free solution, Ginsenoside Re did not affect vasoconstriction. In addition, caffeine- or phenylephrine-stimulated vasoconstriction were not changed by Ginsenoside Re. Either charybdotoxin or glibenclamide could inhibit Ginsenoside Re-caused inhibition of the stimulated vasoconstriction in both human and sheep umbilical vessels, where 4-aminopyridine did not show the similar inhibitory effect. Conclusion-The results provide new information on Shengmai's effects and underlying mechanisms in umbilical vessels. Importantly, the information gained offers interesting potential for developing new drugs acting on umbilical cords for fetal medicine.
\end{abstract}

\section{Keywords}

Shengmai, Umbilical Arteries and Veins, Ginsenoside Re, $\alpha$-Adrenergic Receptor

\footnotetext{
*Corresponding author.

${ }^{\#} \mathrm{X}$. H. Yin and X. X. Gu contributed equally to this work.
}

How to cite this paper: Yin, X.H., Gu, X.X., He, Y., Zhu, D., Chen, J., Wu, J., Feng, X.Q., Li, J.H., Mao, C.P. and Xu, Z.C. (2015) Shengmai Suppressed Vascular Tension in Umbilical Arteries and Veins of Human and Sheep. Pharmacology \& Pharmacy, 6, 281-291. http://dx.doi.org/10.4236/pp.2015.66030 


\section{Vascular Tension}

\section{Introduction}

The umbilical cord with its blood vessels is a major or only pathway between mothers and fetuses, and critical functions of umbilical vessels are to supply and maintain blood flow as well as oxygen and nutrition for fetuses, which is necessary for life in utero [1] [2]. Any condition that can influence blood vessels of umbilical cord, may affect the supply blood and nutrition for fetuses, and may cause in utero hypoxia or fetal growth restriction [3]. Although in utero hypoxia is a common condition in clinic due to multiple factors [4]-[7], there have been limited approaches in dealing with that medical problem. Therefore, finding new drugs or methods against in utero hypoxia related to poor supply of blood flow is a consistent effort in both basic science and clinical work.

Shengmai is one of traditional herbal medicines being used frequently in clinical practice in treatments of various of cardiovascular diseases, including ischemic heart diseases, and stroke [8] [9]. In spite of that, there exist many experimental and clinical studies in demonstration of effects and mechanisms of Shengmai in cardiovascular systems or central blood vessel systems [8], it is unknown if Shengmai has any special vascular influence or effect on blood vessels of umbilical cords. The present study is focused on this topic.

Previous work showed that Shengmai consists of at least three major components, Panax Ginseng, Ophiopogon Japonicus, and Schisandra Chinensis [9]-[11]. Several antioxidant ingredients have been discovered in Panax Ginseng and Schisandra, including Ginseoside Rb1, Ginseoside Rg1, and Ginseoside Re(GRe) from Panax Ginseng and schizandrin from Schisandra [12]. They have been shown in preventing the oxidative damage in heart, brain, and other tissues, and being routinely used in treatment of coronary heart disease [9]. Shengmai also was demonstrated its effects in preventing circulatory shock and brain oxidative and ischemic damage during heatstroke [8]. Moreover, administration of Shengmai right after the onset of heat stroke is still considerably effective way for improving circulatory shock and inhibiting oxidative damage in the brain [8]. As mentioned above, since there has been no data on Shengmai's effects on the umbilical vessels, no information is available on possible influence as well as mechanisms of Shengmai on umbilical vessels. Obviously, addressing such questions is important.

In the present study, we investigated Shengmai's effects on both arteries and veins from human umbilical cords first. Considering inevitable variations among different human subjects, we also used umbilical cords from experimental healthy sheep in testing Shengmai's effects on sheep umbilical vessels. Subsequent experiments determined several key compounds of Shengmai and their vascular effects on umbilical vessels. In addition, we performed preliminary study on possible mechanisms that may be involved in vascular actions of Shengmai or its ingredients on umbilical vessels. Information gained is not only contribution to vascular pharmacology, but also to perinatal medicine and clinical work related to pregnancy.

\section{Materials and Methods}

\subsection{Preparation of the Umbilical Cord Vessels}

Human umbilical cord samples were obtained from 105 women after delivery at term at local hospitals. All deliveries were either vaginal deliveries or elective cesarean deliveries without complications. The median gestation at delivery was 39 weeks \pm 8 days. The reasons for cesarean delivery included previous cesarean section and presumed cephalopelvic disproportion. The median parity value of the women at the time of delivery was 1 (range 0 - 3). There was no evidence of hypertensive disease, gestational diabetes mellitus (GDM) and other diseases for any of the subjects. The mean body mass index (BMI) of those cases was $22.32 \mathrm{~kg} / \mathrm{m}^{2}$ [13]. All procedures were approved by the Institute Committee.

All procedures were approved by the Institute Animal Care Committee and were incompliance with the Guidelines for NIHC are and Use of Laboratory Animals. The animal experiments were performed in chronically instrumented conscious sheep at 128 - 134 days of gestation (term 145 days). Animals were housed in individual study cage and in a light controlled room (12 h light/dark cycles) with food and water provided libitum. All sheep deliveries were elective cesarean deliveries, and umbilical cord samples were obtained immediately. All procedures were approved by the Institute Committee and in compliance with the Guidelines for national in- 
stitute of health (NIH) Care and Use of Laboratory Animals.

Approximately $10 \pm 5 \mathrm{~cm}$ segments were excised from middle part of umbilical cords between the placenta and fetus [13]. Then samples were immediately placed in the modified Krebs-Henseleit solution (K-H solution) at $4^{\circ} \mathrm{C}$ with composition $(\mathrm{mmol} / \mathrm{L}): \mathrm{NaCl}, 119 \mathrm{mmol} / \mathrm{L}, \mathrm{KCl}, 4.7 \mathrm{mmol} / \mathrm{L}, \mathrm{NaHCO}_{3}, 25 \mathrm{mmol} / \mathrm{L}, \mathrm{KH}_{2} \mathrm{PO}_{4}, 1.2$ $\mathrm{mmol} / \mathrm{L}, \mathrm{CaCl}_{2}, 2.5 \mathrm{mmol} / \mathrm{L}, \mathrm{MgSO}_{4}, 1.0 \mathrm{mmol} / \mathrm{L}$, EDTA, $0.004 \mathrm{mmol} / \mathrm{L}$, and D-glucose, $11 \mathrm{mmol} / \mathrm{L}$, at $37^{\circ} \mathrm{C}$ at $\mathrm{pH} 7.4$ with constant bubbling with $95 \% \mathrm{O}_{2} / 5 \% \mathrm{CO}_{2}$ [14]. Samples were used immediately following the preparation.

\subsection{Vascular Experiments}

Umbilical veins and arteries were carefully dissected from umbilical cords by removal of surrounding tissue using micro-dissecting instruments. Vessels were cut in rings with 3 - 5 mm length [13] [15]. Rings were then suspended individually on stainless steel hooks inserted into their lumens and stretched with an initial isometric tension of $2 \mathrm{~g}$, in glass-jacketed organ baths as previously reported [16] [17]. Each bath contained $5 \mathrm{ml}$ of K-H solution, $\mathrm{pH} 7.35-7.45$, at $37^{\circ} \mathrm{C}$, and constant bubbling with a mixture of $95 \%$ oxygen $/ 5 \%$ carbon dioxide [18]. The upper hook was connected to a force transducer and changes in isometric force were recorded using PowerLab system with Chart 7.0 software (AD Instruments, Australia). Rings were allowed to equilibrate for $120 \mathrm{mi}-$ nutes. During that period bath solution was replaced every 15 minutes with fresh K-H solution.

After 120 min of equilibration, each ring was contracted using $\mathrm{KCl}(60 \mathrm{mM})$ for reaching a maximum response, and then washed out. The $\mathrm{KCl}$ challenge was performed three times to test functional state of the vascular tissue. Optimal tension was adjusted throughout the equilibration period. After the last $\mathrm{KCl}$ challenge, a 30 40 minutes recovery period was allowed [14]. Following drugs were tested in the experiments.

The effect of Shengmai on human umbilical vein/artery (HUV/HUA) or sheep umbilical vein/artery (SUV/ SUA) rings: When the rings were equilibrated, phenylephrine (PE, $\left.10^{-4} \mathrm{~mol} / \mathrm{L}\right)$ was added to produce steady contraction, and then Shengmai $\left(10^{-4} \mathrm{~mol} / \mathrm{L}\right)$ was applied. Vascular reactions were monitored for $120 \mathrm{~min}$.

When the rings were equilibrated, NG-Nitro-L-arginine Methyl Ester (L-NAME, the nitric oxide synthase (eNOS) inhibitor, $\left.10^{-5} \mathrm{~mol} / \mathrm{L}\right)$ for 30 minutes and PE $\left(10^{-4} \mathrm{~mol} / \mathrm{L}\right)$ was added to produce steady contraction, and then $10^{-4} \mathrm{~mol} / \mathrm{L}$ Shengmai was applied. Vascular reactions were monitored for at least 120 minutes.

When the sheep umbilical rings were equilibrated, following PE $\left(10^{-4} \mathrm{~mol} / \mathrm{L}\right)$ to produce steady contraction, Following key elements of Shengmaiwere used in testing: GRe $\left(10^{-4} \mathrm{~mol} / \mathrm{L}\right)$, Ginsenoside $\mathrm{Rb} 1\left(10^{-4} \mathrm{~mol} / \mathrm{L}\right)$, Ginsenoside Rg1 $\left(10^{-4} \mathrm{~mol} / \mathrm{L}\right)$, or Schisandrin $\left(10^{-4} \mathrm{~mol} / \mathrm{L}\right)$ was added separately. Vessel tone was monitored and recorded for at least 120 minutes after adding the drug.

$\mathrm{CaCl}_{2}$ dose-effect curve: SUV/SUA rings were washed 2 - 3 times with $\mathrm{Ca}^{2+}$-free $\mathrm{K}-\mathrm{H}$ solution (containing 1 $\mu \mathrm{M}$ EGTA). The vessel rings were preincubated with GRe $\left(10^{-4} \mathrm{~mol} / \mathrm{L}\right)$ for 30 minutes before application of $\mathrm{KCl}(60 \mathrm{mM}) . \mathrm{CaCl}_{2}$ was then added cumulatively $\left(0.25-5 \times 10^{-5} \mathrm{~mol} / \mathrm{L}\right)$. The vehicle, instead of GRe, was used for the control group before add $\mathrm{KCl}(60 \mathrm{mM})$.

The effect of GRe on PE- or caffeine-induced contractions in SUV/SUA rings was tested in $\mathrm{Ca}^{2+}$-free K-H solution. The SUV/SUA rings were washed 2 - 3 times with $\mathrm{Ca}^{2+}$-free $\mathrm{K}-\mathrm{H}$ solution. The rings were exposed to GRe $\left(10^{-4} \mathrm{~mol} / \mathrm{L}\right)$ for 30 minutes, and then add $10^{-5} \mathrm{~mol} / \mathrm{L}$ PE or $20 \mathrm{mmol} / \mathrm{L}$ caffeine.

The effect of potassium channel antagonists on SUV/SUA rings was tested. Different potassium channel antagonists were applied 30 minutes before the addition of PE $\left(10^{-4} \mathrm{~mol} / \mathrm{L}\right)$. 4-aminopyridine $\left(4-\mathrm{AP}, 10^{-3} \mathrm{~mol} / \mathrm{L}\right.$ [19], Voltage-dependent $\mathrm{K}^{+}(\mathrm{Kv})$ channels antagonist [19] [20], charybdotoxin (CTX, $10^{-7} \mathrm{~mol} / \mathrm{L}$ [20], $\mathrm{Ca}^{2+}$-activated $\mathrm{K}^{+}$(BKCa) channels antagonist [20]), Glibenclamide $\left(10^{-6} \mathrm{~mol} / \mathrm{L}\right.$ [19], ATP-sensitive $\mathrm{K}^{+}$(KATP) channels antagonist [19] [20], or vehicle were used. Following steady vasoconstriction by PE $\left(10^{-4} \mathrm{~mol} / \mathrm{L}\right)$, GRe $\left(10^{-4} \mathrm{~mol} / \mathrm{L}\right)$ was added into the bath, and vascular responses were monitored and recorded for at least $120 \mathrm{mi}-$ nutes.

\subsection{Drugs and Solutions}

The modified K-H solution: NaCl, $119 \mathrm{mmol} / \mathrm{L}, \mathrm{KCl}, 4.7 \mathrm{mmol} / \mathrm{L}, \mathrm{NaHCO}_{3}, 25 \mathrm{mmol} / \mathrm{L}, \mathrm{KH}_{2} \mathrm{PO}_{4}, 1.2 \mathrm{mmol} / \mathrm{L}$, $\mathrm{CaCl}_{2}, 2.5 \mathrm{mmol} / \mathrm{L}, \mathrm{MgSO}_{4}, 1.0 \mathrm{mmol} / \mathrm{L}$, EDTA, $0.004 \mathrm{mmol} / \mathrm{L}$, and glucose, $11 \mathrm{mmol} / \mathrm{L}$.

Shengmai was purchased from Suzhong Pharnaceutical Group (Jiangsu, China). GRe, Ginsenoside Rb1, Ginsenoside Rg1, and Schisandrol were purchased from Shanghai Sunny Biotech Co., Ltd. (Shanghai, China). Phenylephrine, NG-Nitro-L-arginine Methyl Ester (L-NAME), 4-AP, CTX, and Gli were purchased from Sigma- 
Aldrich (USA).

\subsection{Statistical Analysis}

All data were expressed as means \pm SEMs, the date was calculated from the concentration-response curve resulting performed by Graph Pad Prism (Version 5.01, Graph Pad Software Inc., La Jolla, CA, USA). All analog signals were recorded continuously throughout the study, and then digitized on a computer with Med-Lab acquisition software. And differences were evaluated for statistically significance $(\mathrm{P}<0.05)$ by two-way ANOVA or t-test.

\section{Results}

\subsection{The Effect of Shanghai on HUV/HUA and SUV/SUA}

PE $\left(10^{-4} \mathrm{~mol} / \mathrm{L}\right)$ produced a concentration-related vasoconstriction in the HUV/HUA rings, where Shengmai $\left(10^{-4} \mathrm{~mol} / \mathrm{L}\right)$ could suppress PE-mediated vasoconstrictions significantly in the HUV/HUA rings (Figure 1 ).

After $120 \mathrm{~min}$ of equilibration, $\mathrm{PE}\left(10^{-4} \mathrm{~mol} / \mathrm{L}\right)$ produced a dose-dependent vasoconstriction in the SUV/SUA rings, where Shengmai $\left(10^{-4} \mathrm{~mol} / \mathrm{L}\right)$ produced significant suppressed PE-mediated vasoconstriction in the SUV/ SUA rings (Figure 2).

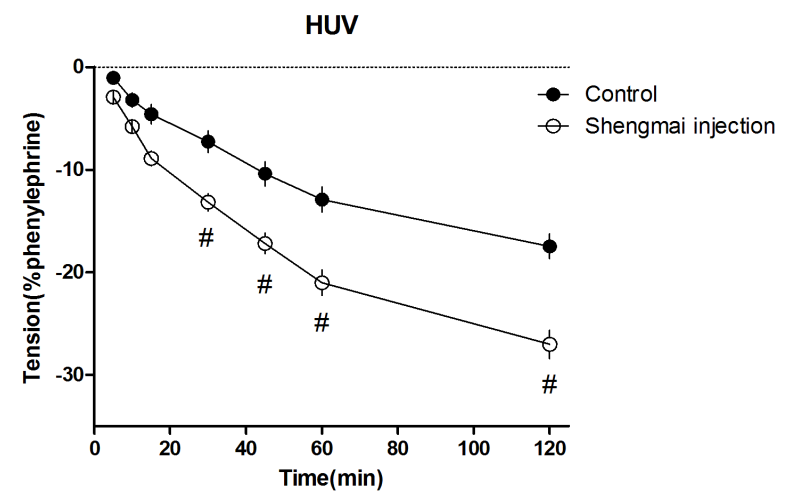

(a)

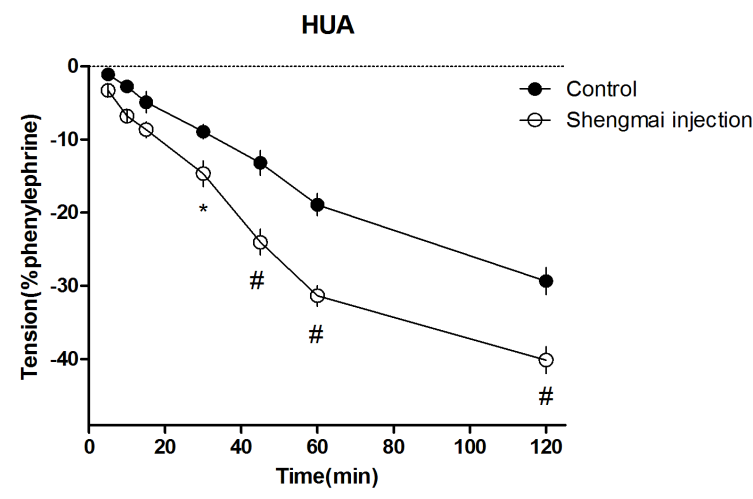

(b)

Figure 1. Shengmai suppressed phenylephrine-stimulated vasoconstrictions in human umbilical vein/artery (HUV/HUA). ((a): HUV $n=105$ rings from 94 umbilical cords; (b): HUA $n=110$ rings from 94 umbilical cords). Control vs Shengmai, $\# \mathrm{P}<0.01, * \mathrm{P}<0.05$.

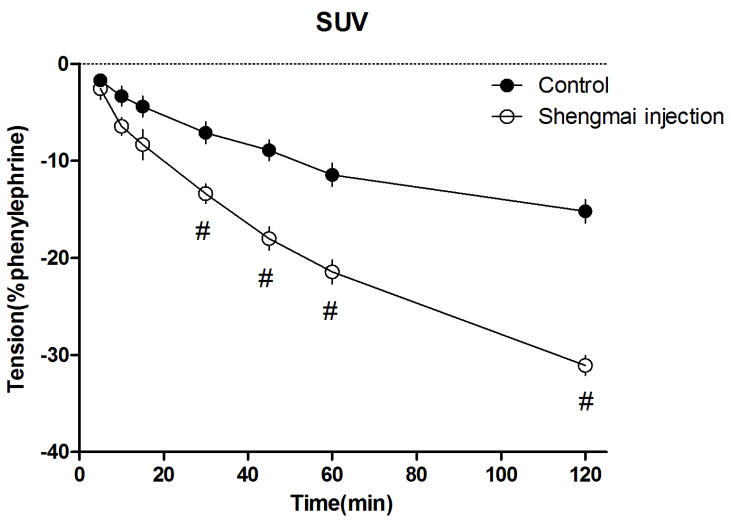

(a)

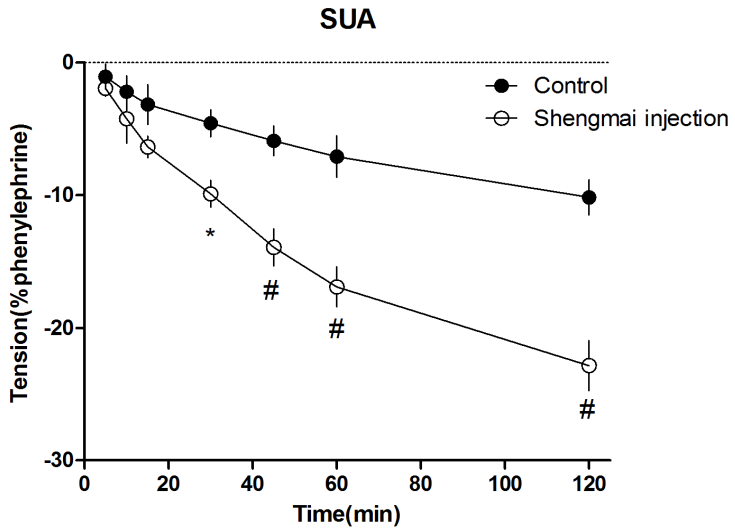

(b)

Figure 2. Shengmai suppressed phenylephrine-stimulated vasoconstrictions in sheep umbilical vein/artery (SUV/SUA) ((a): SUV $n=48$ rings from 6 umbilical cords; (b): SUA $n=44$ rings from 6 umbilical cords). Control vs Shengmai, \#P $<0.01$, $* \mathrm{P}<0.05$. 


\subsection{The effect of L-NAME on HUV/HUA and SUV/SUA}

After 120 min of equilibration, PE $\left(10^{-4} \mathrm{~mol} / \mathrm{L}\right)$ produced dose-dependent contractions in HUV/HUA and SUV/ SUA rings. There was no significant difference in the Shengmai-suppressed vascular tension between the groups with or without L-NAME (Figure 3(A), Figure 3(B)).

\subsection{The effect of Key Compounds of Shengmai on SUV/SUA}

Following PE $\left(10^{-4} \mathrm{~mol} / \mathrm{L}\right)$-produced steady vasoconstriction, Ginsenoside Re, Ginsenoside Rb1, Ginsenoside Rg1, or Schisandrin was added. GRe $\left(10^{-4} \mathrm{~mol} / \mathrm{L}\right)$ suppressed PE-stimulated vasoconstrictions in SUV/SUA rings, where Ginsenoside Rb1 $\left(10^{-4} \mathrm{~mol} / \mathrm{L}\right)$, Ginsenoside $\operatorname{Rg} 1\left(10^{-4} \mathrm{~mol} / \mathrm{L}\right)$, and Schisandrin $\left(10^{-4} \mathrm{~mol} / \mathrm{L}\right)$ did not cause significant changes (Figure 4).

\section{4. $\mathrm{CaCl}_{2}$ Dose-Effect Curve}

Following the rings were equilibrated in $\mathrm{Ca}^{2+}$-free $\mathrm{K}-\mathrm{H}$ solution, Ginsenoside $\mathrm{Re}\left(10^{-4} \mathrm{~mol} / \mathrm{L}\right)$ was added $30 \mathrm{~min}$ before application of $\mathrm{KCl}$ to produce steady contraction. $\mathrm{CaCl}_{2}$ was then added cumulatively. There was no statistical significance in vascular responses between the control and GRe groups (Figure 5).

\subsection{The Effect of GRe on PE- or Caffeine-Induced Contractions in SUV/SUA}

Following the rings were equilibrated in $\mathrm{Ca}^{2+}$-free K-H solution and pre-treatment with GRe for 30 min, PE or

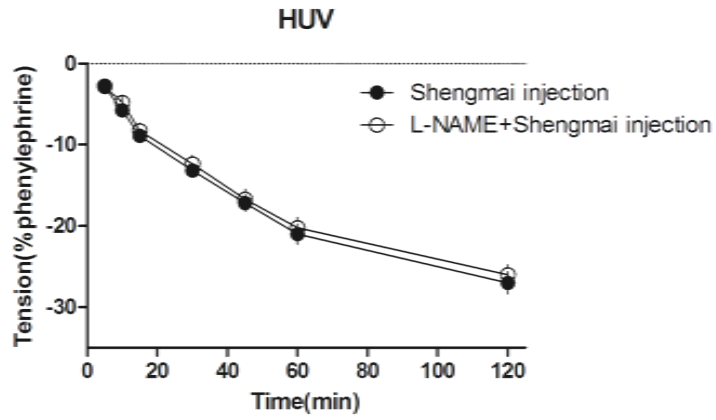

(a)

SUV

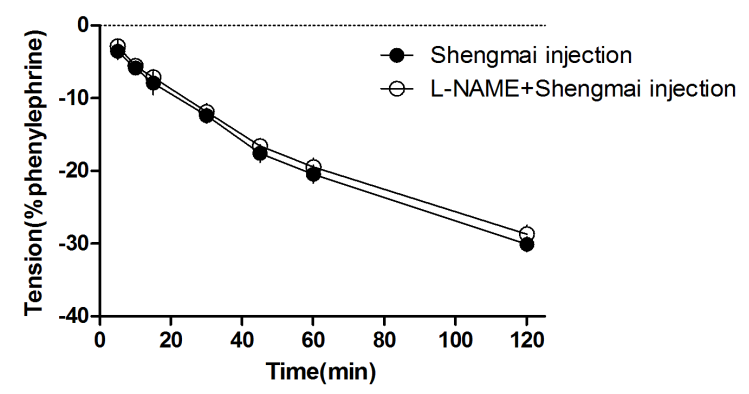

(a)

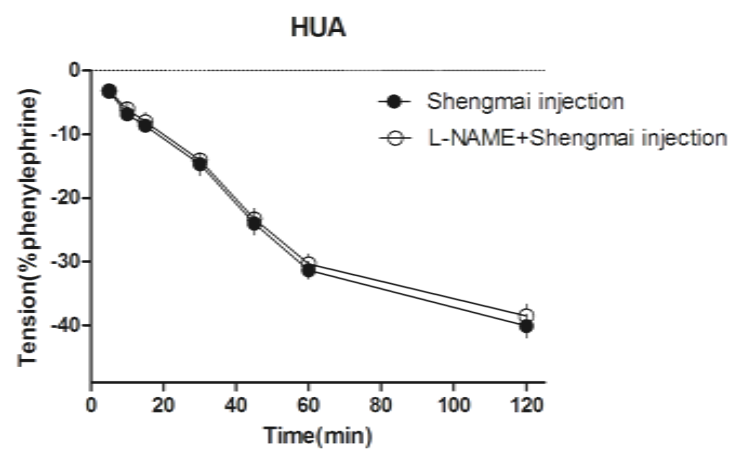

(b)

(A)

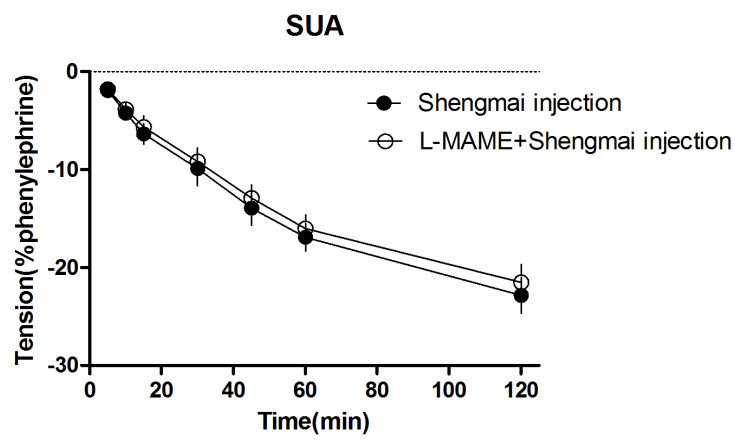

(b)

(B)

Figure 3. (A) Pre-treatment with NG-Nitro-L-arginine Methyl Ester (L-NAME) had no influence on Shengmai-suppressed vasoconstriction by phenylephrine in human umbilical vein/artery (HUV/HUA) ((a): HUV $n=105$ rings from 90 umbilical cords; (b): HUA n = 110 rings from 94 umbilical cords); (B) Pre-treatment with NG-Nitro-L-arginine Methyl Ester (L-NAME) had no influence on Shanghai-suppressed phenylephrine-stimulated vasoconstrictions in sheep umbilical vein/ artery ((a): SUV n $=48$ rings from 6 umbilical cords; (b): SUA $n=44$ rings from 6 umbilical cords). L-NAME + Shangmai: Following pre-treatment with L-NAME, Shanghai was added into the organ bath. 


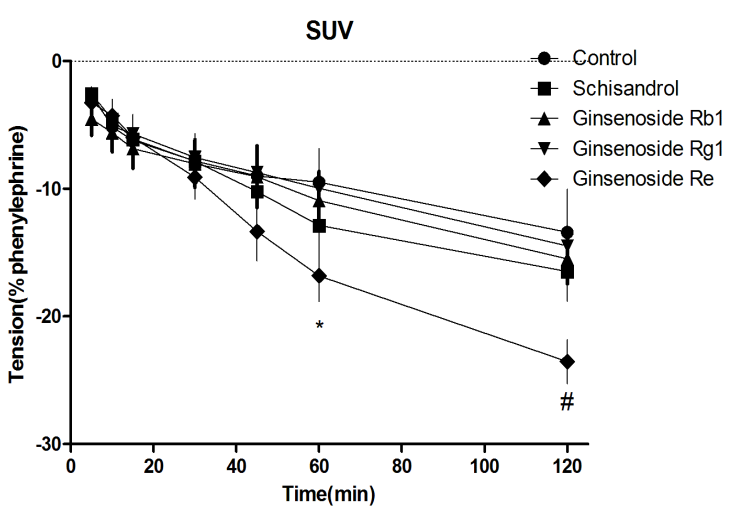

(a)

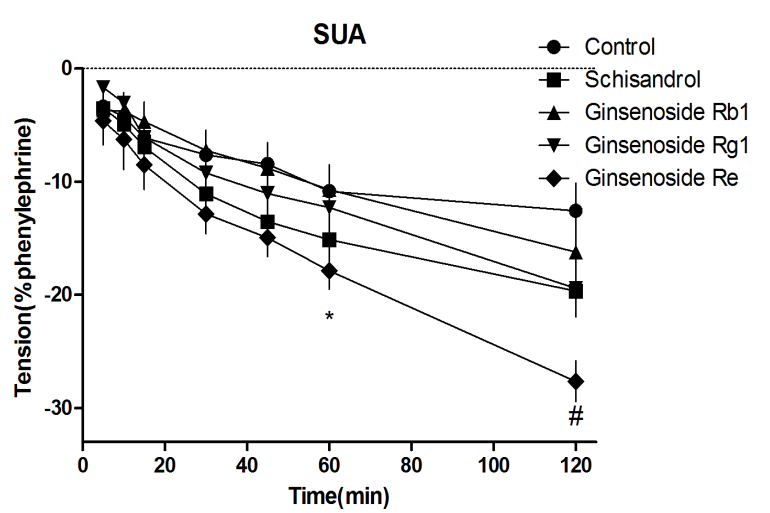

(b)

Figure 4. The effect of Ginsenoside Re, Ginsenoside Rb1, Ginsenoside Rg1, or Schisandrin on sheep umbilical vein/artery (SUV/SUA) stimulated by phenylephrine ((a): SUV $n=43$ rings from 10 umbilical cords; (b): SUA $n=45$ rings from 10 umbilical cords). Control vs Ginsenoside Re, \#P $<0.01$, $* \mathrm{P}<0.05$.

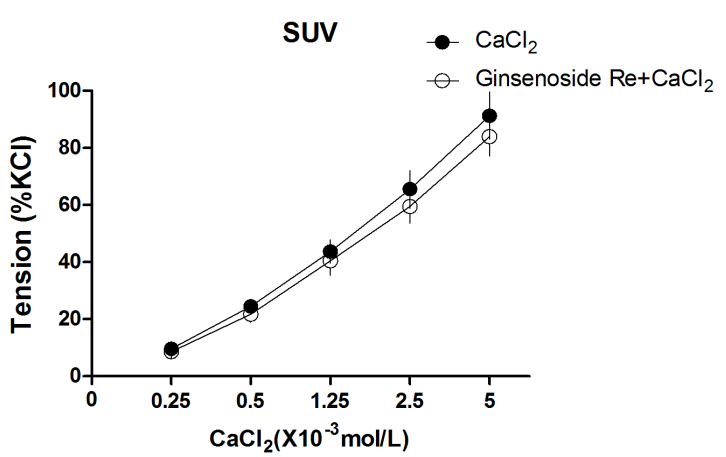

(a)

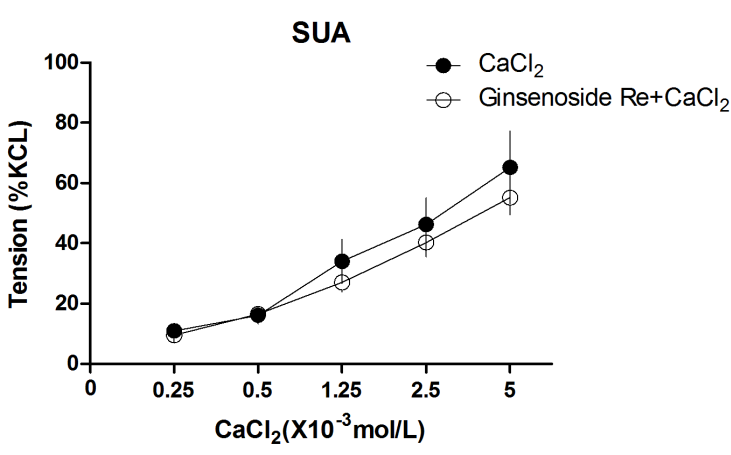

(b)

Figure 5. The effect of $\mathrm{CaCl}_{2}$ on sheep umbilical vein/artery (SUV/SUA) ((a): SUV $\mathrm{n}=24$ rings from 6 umbilical cords; (b): SUA $n=20$ rings from 6 umbilical cords).

caffeine was then applied. There was no significant difference in vascular responses between the control and GRe group ( $\mathrm{P}>0.05$ ) in both SUV and SUA (Figure 6).

\subsection{The Effect of Potassium Channel Antagonists on Ginsenoside Re-Induced Relaxation in SUV/SUA}

Either CTX $\left(10^{-7} \mathrm{~mol} / \mathrm{L}\right)$ or Glibenclamide $\left(10^{-6} \mathrm{~mol} / \mathrm{L}\right)$ significantly reduced the GRe-suppressed vascular tension in SUV/SUA. However, the pre-treatment with $4-\mathrm{AP}\left(10^{-3} \mathrm{~mol} / \mathrm{L}\right)$ did not change the vascular responsecaused by GRe (Figure 7).

\section{Discussion}

A number of clinical and experimental investigations have demonstrated the cardiovascular effects of Shengmai, and Shengmai has been often used in clinical treatments against stroke and cardiovascular diseases, including coronary heart disease, atherosclerosis, and hypertension [8] [9]. It is recently confirmed that blood vessels in umbilical cords can act differently from other vascular systems to chemical stimulation. However, there was no information regarding effects of Shengmai on either arteries and veins of umbilical cords as background of this study. Importantly, the umbilical cord serves as only important pathway between pregnant mothers and fetuses for supply of blood, oxygen, and nutrition. Thus, understanding influence of various chemicals or drugs on umbilical vessels is very important to perinatal medicine.

In the present study, Shengmai induced a significant decrease of vascular tone-stimulated by phenylephrine in both human and sheep umbilical arteries and veins, demonstrating that Shengmai could cause vasodilation or 
suV

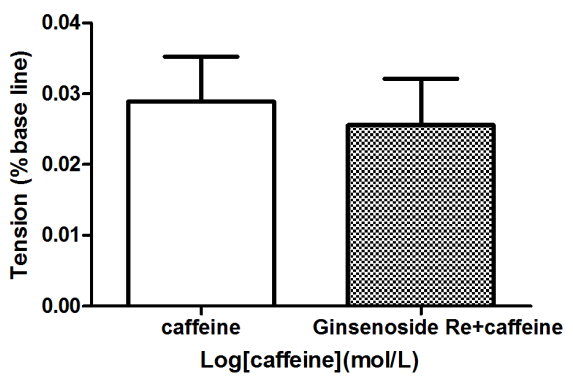

(a)

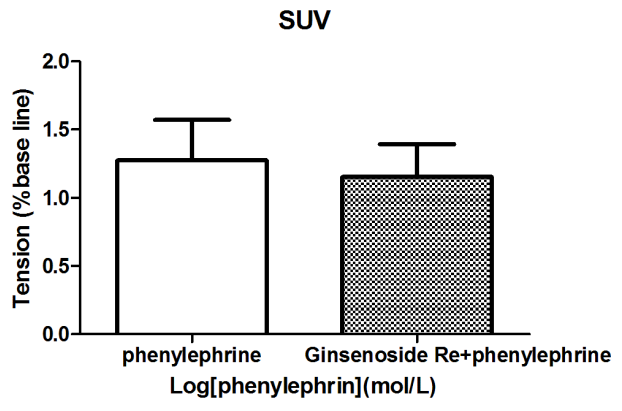

(c)

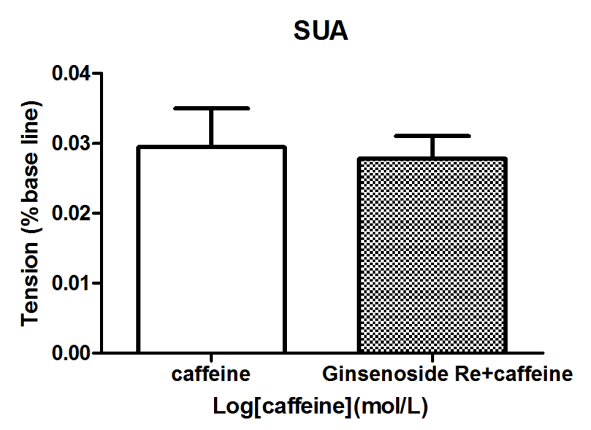

(b)

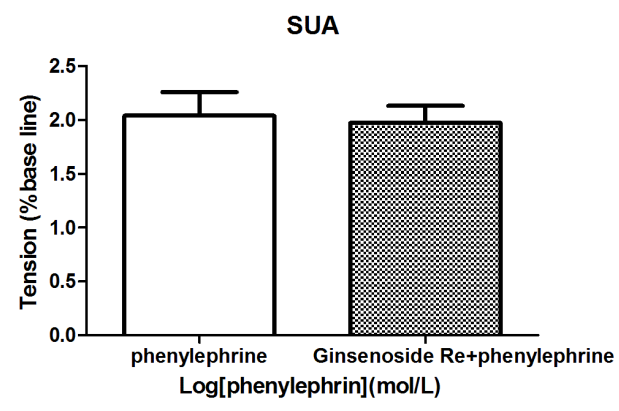

(d)

Figure 6. The effect of Ginsenoside Reon sheep umbilical vein/artery (SUV/SUA) stimulated by phenylephrine or caffeine ((a): SUV $n=24$ rings from 6 umbilical cords; (b): SUA $n=20$ rings from 6 umbilical cords).

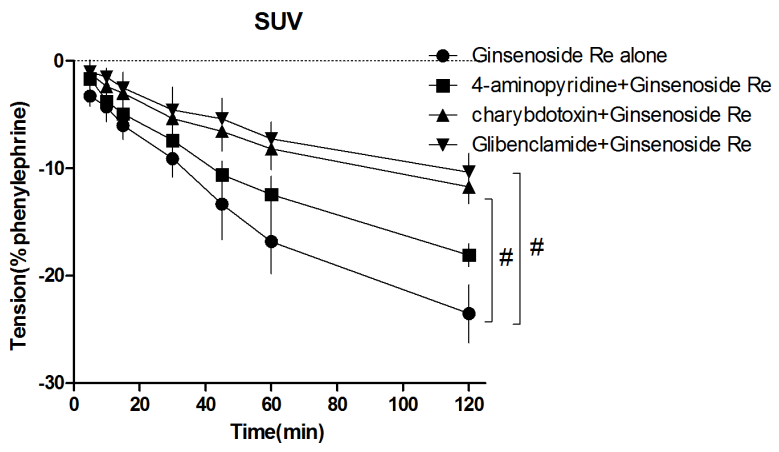

(a)

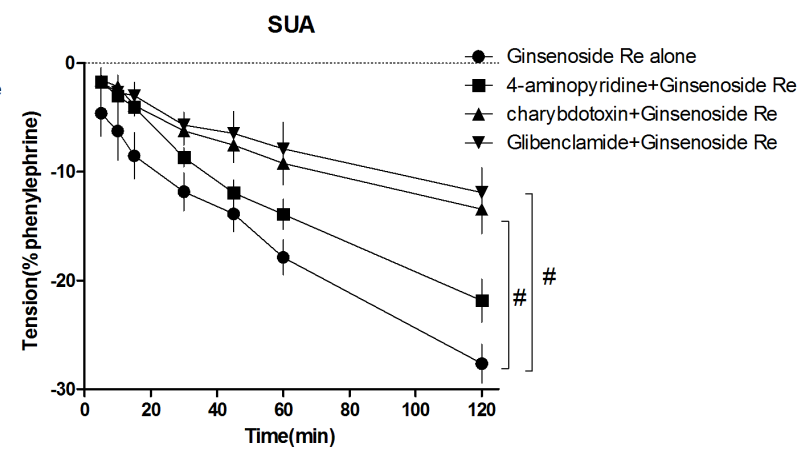

(b)

Figure 7. The effect of potassiumchannels antagonists on Ginsenoside Re-suppressed vascular tension in sheep umbilical vein/artery (SUV/SUA) ((a): SUV n = 36 rings from 8 umbilical cords; (b): SUA $n=34$ rings from 8 umbilical cords). Ginsenoside Re alone vs charybdotoxin; Ginsenoside Re vs Glibenclamide, \#P $<0.01$.

suppress phenylephrine-produced vascular tension. Notably, this was the first study to show the effects of Shengmai on umbilical cords. Significance of the findings includes that may offer new opportunities for developing novel drugs or approaches targeting at regulations of umbilical cord blood vessels. For example, many clinical conditions may lead to in utero hypoxia as well as fetal growth restriction [4]. Increasing of umbilical blood flow could be helpful for those conditions. Thus, the Shengmai's effects on umbilical vessels may have great potentials in the field.

In the present study, possible mechanisms of Shengmai-suppress vasoconstriction by PE in the umbilical cord vessels were determined. The first possibility we considered was contribution from nitric oxide (NO) signaling pathway. It is well known that NO mainly from the endothelium in vascular systems, and plays critical roles in vascular relaxation [21] [22]. Damage of vascular endothelium or NO pathways may cause disability of vascular functions, particularly vasodilation [23]-[26]. In our experiments, following the pre-treatment with L-NAME in both human and sheep vessels, no significant changes was observed in Shengmai-mediated vascular responses, 
suggesting that Shengmai-produced vascular relaxation may not rely on NO.

Shengmai is a traditional herb medicine with many ingredients. Major biological compounds in Shengmai include Ginsenoside Re, Ginsenoside Rb1, Ginsenoside Rg1, and Schisandrin [12]. Previous study using those key compounds of Shengmai showed vascular effects on other vessel systems [27]-[30], including anti-oxidative influence [31] and inhibition of P-glycoprotein [32] [33]. It was unknown whether any of those four elements play major roles in Shengmai-mediated vascular dilation in umbilical cords. In the present study, we found Shengmai-produced vasodilation mainly depend on GRe, not other three compounds tested. Again, this is a new finding in demonstration of that GRe in Shengmai is critical for the suppression of PE-induced vasoconstriction effect in umbilical cord vessels.

After excluding possibility of NO involved, other mechanisms, including calcium and potassium signaling pathways, were considered in smooth muscle of umbilical vessels. Vascular smooth muscle requires $\mathrm{Ca}^{2+}$ for constrictions either from intracellular stores or the influx of extra-cellular $\mathrm{Ca}^{2+}$. The major routes of $\mathrm{Ca}^{2+}$ influx include receptor-operated $\mathrm{Ca}^{2+}$ channel (ROCC) [34] and voltage-gated $\mathrm{Ca}^{2+}$ channel (VGCC) [35] [36]. PE is a $\alpha$-adrenergic receptor agonist [37] that produces vasoconstriction mainly via VGCC. Extra-cellular high potassium makes VGCCs to open in response to membrane depolarization and allow $\mathrm{Ca}^{2+}$ ions to enter cells [38] and induce vasoconstriction. $\mathrm{CaCl}_{2}$ could cause dose-dependent vasoconstriction linked to $\mathrm{Ca}^{2+}$ influx [36] [39]. Our study demonstrated that Shengmai and Ginsenoside Re could suppress PE-induced vasoconstriction in umbilical vessel rings. When the vessel rings were equilibrated in $\mathrm{Ca}^{2+}$-free $\mathrm{K}-\mathrm{H}$ solution with $\mathrm{GRe}, \mathrm{CaCl}_{2}$ was then added into the bath cumulatively. This treatment could not change the $\mathrm{Ca}^{2+}$ influx induced vasoconstriction in both umbilical arteries and veins, indicating that GRe-suppressed vascular tension may not be related to VGCC-mediated intracellular $\mathrm{Ca}^{2+}$ influx.

The sarcoplasmic reticulum (SR) can release stored $\mathrm{Ca}^{2+}$ in cells [40]. Caffeine could induce transient vasoconstriction mainly by $\mathrm{Ca}^{2+}$ release from the SR, where the $\mathrm{SR} \mathrm{Ca}^{2+}$ flux is mediated by ryanodine receptors that can be opened in response to small trigger $\mathrm{Ca}^{2+}$ stimulation [41]. In $\mathrm{Ca}^{2+}$-free $\mathrm{K}-\mathrm{H}$ solution, PE-induced vasoconstriction was induced by activating IP3 (1, 4, 5-trisphosphate)-sensitivity calcium channels [42]. In the present study, GRe could not affect caffeine- or PE-induced vasoconstriction in $\mathrm{Ca}^{2+}$-free $\mathrm{K}-\mathrm{H}$ solution, suggesting that GRe-induced vascular tension may not be related to the $\mathrm{Ca}^{2+}$ release via the SR or IP3-sensitivity calcium pool [43].

Potassium channels integrate a variety of vasoactive signals to dilate or constrict blood vesselsvia regulations of the membrane potential (depolarization or hyper-polarization) in smooth muscle cells [20] [44]. In order to test the relationship between Shengmai- or GRe-induced vasodilation and $\mathrm{K}^{+}$channels, we determined the effects of the different antagonists on $\mathrm{K}^{+}$channels, including 4-AP, Glibenclamide, and CTX. The pre-treatment of vessel rings with 4-AP had no effects on the GRe-suppressed vascular tension. However, either CTX or Glibenclamide significantly reduced GRe-suppressed vessel tension inumbilical vessels. The results demonstrated that the Shengmai-mediate umbilical vascular response was related to potassium channel pathways. Since 4-AP had no influence on GRe-produced vascular changes, while CTX and Glibenclamide inhibited the effect of GRe, the data indicated that $\mathrm{Ca}^{2+}$-activated $\mathrm{K}^{+}$channels and ATP-sensitive channels, not voltage-dependent $\mathrm{K}^{+}$channels, might play a role in the GRe- and Shengmai-suppressed vascular tension.

\section{Conclusion}

This was the first study to show that Shengmai and its compound GRe could suppress vascular tension-generated by PE in the umbilical cord. Since Shengmai could be used during pregnancy, the data increased understanding the effects of this herb drug on umbilical vessels. The possible mechanisms for Shengmai-reduced vascular tonemay not be related to NO pathways in the umbilical cords, and may not be linked to release of intracellular $\mathrm{Ca}^{2+}$ orentry of extra-cellular $\mathrm{Ca}^{2+}$. However, potassium channels, particularly BKCa channels and ATP-sensitive channels, may play an important role in the GRe-suppressed vascular tension. Although further studies are required for detailed mechanisms of Shengmai on umbilical vessels, the new information gained in this study offers insight for understanding Shengmai's effects on umbilical cords.

\section{Acknowledgements}

Thanks to all the pregnant mothers and their families who participated in this study. This work was supported by Grant 2012CB947604; 2013BAI04B05; NSFC (81030006, 81320108006, 81370719, and 81370714); N3126908; 
Jiangsu Key Discipline/Laboratory and “Chuang XinTuan Dui” funds; and Jiangsu Key Discipline of Human Assisted Reproduction Medicine funds.

\section{Conflict of Interest}

The authors declare that they have no conflict of interest.

\section{References}

[1] Antoniou, E.E., Derom, C., Thiery, E., Fowler, T., Southwood, T.R. and Zeegers, M.P. (2011) The Influence of Genetic and Environmental Factors on the Etiology of the Human Umbilical Cord: The East Flanders Prospective Twin Survey. Biology of Reproduction, 85, 137-143. http://dx.doi.org/10.1095/biolreprod.110.088807

[2] Imamura, T., Potempa, J. and Travis, J. (2004) Activation of the Kallikrein-Kinin System and Release of New Kinins through Alternative Cleavage of Kininogens by Microbial and Human Cell Proteinases. Biological Chemistry, 385, 989-996. http://dx.doi.org/10.1515/BC.2004.129

[3] Ferguson, V.L. and Dodson, R.B. (2009) Bioengineering Aspects of the Umbilical Cord. European Journal of Obstetrics \& Gynecology, 144, S108-S113. http://dx.doi.org/10.1016/j.ejogrb.2009.02.024

[4] Whitehead, C.L., Teh, W.T., Walker, S.P., Leung, C., Larmour, L. and Tong, S. (2013) Circulating MicroRNAs in Maternal Blood as Potential Biomarkers for Fetal Hypoxia in-Utero. PLoS ONE, 8, e78487. http://dx.doi.org/10.1371/journal.pone.0078487

[5] Smith, G.C. and Fretts, R.C. (2007) Stillbirth. The Lancet, 370, 1715-1725. http://dx.doi.org/10.1016/S0140-6736(07)61723-1

[6] Froen, J.F., Gardosi, J.O., Thurmann, A., Francis, A. and Stray-Pedersen, B. (2004) Restricted Fetal Growth in Sudden Intrauterine Unexplained Death. Acta Obstetricia et Gynecologica Scandinavica, 83, 801-807. http://dx.doi.org/10.1080/j.0001-6349.2004.00602.x

[7] Lawn, J.E., Cousens, S. and Zupan, J. (2005) 4 Million Neonatal Deaths: When? Where? Why? The Lancet, 365, 891900. http://dx.doi.org/10.1016/S0140-6736(05)71048-5

[8] Nishida, H., Kushida, M., Nakajima, Y., Ogawa, Y., Tatewaki, N., Sato, S., et al. (2007) Amyloid-Beta-Induced Cytotoxicity of PC-12 Cell Was Attenuated by Shengmai-San through Redox Regulation and Outgrowth Induction. Journal of Pharmacological Sciences, 104, 73-81. http://dx.doi.org/10.1254/jphs.FP0070100

[9] Wang, N.L., Liou, Y.L., Lin, M.T., Lin, C.L. and Chang, C.K. (2005) Chinese Herbal Medicine, Shengmai San, Is Effective for Improving Circulatory Shock and Oxidative Damage in the Brain during Heatstroke. Journal of Pharmacological Sciences, 97, 253-265. http://dx.doi.org/10.1254/jphs.FP0040793

[10] Zhao, M.H., Rong, Y.Z. and Lu, B.J. (1996) [Effect of Shengmaisan on Serum Lipid Peroxidation in Acute Viral Myocarditis]. Chinese Journal of Integrated Traditional and Western, 16, 142-145.

[11] Fang, J., Jiang, J. and Luo, D.C. (1987) [Effect of Sheng Mai Decoction on Left Ventricular Function in Patients with Coronary Heart Disease. A Randomized, Double-Blind, Placebo-Controlled, Cross-Over Trial]. Chinese Journal of Internal Medicine, 26, 403-406.

[12] Zhan, S., Guo, W., Shao, Q., Fan, X., Li, Z. and Cheng, Y. (2014) A Pharmacokinetic and Pharmacodynamic Study of Drug-Drug Interaction between Ginsenoside Rg1, Ginsenoside Rb1 and Schizandrin after Intravenous Administration to Rats. Journal of Ethnopharmacology, 152, 333-339. http://dx.doi.org/10.1016/j.jep.2014.01.014

[13] Hehir, M.P., Moynihan, A.T., Glavey, S.V. and Morrison, J.J. (2009) Umbilical Artery Tone in Maternal Obesity. Reproductive Biology and Endocrinology, 7, 6. http://dx.doi.org/10.1186/1477-7827-7-6

[14] Pujol Lereis, V.A., Hita, F.J., Gobbi, M.D., Verdi, M.G. and Rodriguez, M.C. (2006) Rothlin RP. Pharmacological Characterization of Muscarinic Receptor Subtypes Mediating Vasoconstriction of Human Umbilical Vein. British Journal of Pharmacology, 147, 516-523. http://dx.doi.org/10.1038/sj.bjp.0706654

[15] Errasti, A.E., Velo, M.P., Torres, R.M., Sardi, S.P. and Rothlin, R.P. (1999) Characterization of Alpha1-Adrenoceptor Subtypes Mediating Vasoconstriction in Human Umbilical Vein. British Journal of Pharmacology, 126, 437-442. http://dx.doi.org/10.1038/sj.bjp.0702320

[16] Dennedy, M.C., Houlihan, D.D., McMillan, H. and Morrison, J.J. (2002) $\beta_{2^{-}}$and $\beta_{3}$-Adrenoreceptor Agonists: Human Myometrial Selectivity and Effects on Umbilical Artery Tone. American Journal of Obstetrics and Gynecology, 187, 641-647. http://dx.doi.org/10.1067/mob.2002.125277

[17] Potter, S.M., Dennedy, M.C. and Morrison, J.J. (2002) Corticosteroids and Fetal Vasculature: Effects of Hydrocortisone, Dexamethasone and Betamethasone on Human Umbilical Artery. BJOG: An International Journal of Obstetrics \& Gynaecology, 109, 1126-1131. http://dx.doi.org/10.1111/j.1471-0528.2002.01540.x 
[18] Topal, G., Foudi, N., Uydes-Dogan, B.S., Cachina, T., Kucur, M., Gezer, A., et al. (2010) Involvement of Prostaglandin F2alpha in Preeclamptic Human Umbilical Vein Vasospasm: A Role of Prostaglandin F and Thromboxane A2 Receptors. Journal of Hypertension, 28, 2438-2445.

[19] Lam, F.F., Deng, S.Y., Ng, E.S., Yeung, J.H., Kwan, Y.W., Lau, C.B., et al. (2010) Mechanisms of the Relaxant Effect of a Danshen and Gegen Formulation on Rat Isolated Cerebral Basilar Artery. Journal of Ethnopharmacology, 132, 186-192. http://dx.doi.org/10.1016/j.jep.2010.08.015

[20] Nelson, M.T. and Quayle, J.M. (1995) Physiological Roles and Properties of Potassium Channels in Arterial Smooth Muscle. American Journal of Physiology, 268, C799-C822.

[21] Gao, W., Dong, X., Xie, N., Zhou, C., Fan, Y., Chen, G., et al. (2014) Dehydroabietic Acid Isolated from Commiphora opobalsamum Causes Endothelium-Dependent Relaxation of Pulmonary Artery via PI3K/Akt-eNOS Signaling Pathway. Molecules, 19, 8503-8517. http://dx.doi.org/10.3390/molecules19068503

[22] Gauthier, K.M., Campbell, W.B. and McNeish, A.J. (2014) Regulation of $\mathrm{K}_{\mathrm{Ca}} 2.3$ and Endothelium-Dependent Hyperpolarization (EDH) in the Rat Middle Cerebral Artery: The Role of Lipoxygenase Metabolites and Isoprostanes. PeerJ, 2, e414. http://dx.doi.org/10.7717/peerj.414

[23] Shamsuzzaman, A.S., Gersh, B.J. and Somers, V.K. (2003) Obstructive Sleep Apnea: Implications for Cardiac and Vascular Disease. The Journal of the American Medical Association, 290, 1906-1914. http://dx.doi.org/10.1001/jama.290.14.1906

[24] Phillips, B.G., Narkiewicz, K., Pesek, C.A., Haynes, W.G., Dyken, M.E. and Somers, V.K. (1999) Effects of obstructive Sleep Apnea on Endothelin-1 and Blood Pressure. Journal of Hypertension, 17, 61-66. http://dx.doi.org/10.1097/00004872-199917010-00010

[25] Allahdadi, K.J., Walker, B.R. and Kanagy, N.L. (2005) Augmented Endothelin Vasoconstriction in Intermittent Hypoxia-Induced Hypertension. Hypertension, 45, 705-709. http://dx.doi.org/10.1161/01.HYP.0000153794.52852.04

[26] Sumpio, B.E., Riley, J.T. and Dardik, A. (2002) Cells in Focus: Endothelial Cell. The International Journal of Biochemistry \& Cell Biology, 34, 1508-1512. http://dx.doi.org/10.1016/S1357-2725(02)00075-4

[27] Wang, L., Zhang, Y., Wang, Z., Li, S., Min, G., Chen, J., et al. (2012) Inhibitory Effect of Ginsenoside-Rd on Carrageenan-Induced Inflammation in Rats. Canadian Journal of Physiology and Pharmacology, 90, 229-236. http://dx.doi.org/10.1139/y11-127

[28] Kou, J., Tian, Y., Tang, Y., Yan, J. and Yu, B. (2006) Antithrombotic Activities of Aqueous Extract from Radix Ophiopogon Japonicus and Its Two Constituents. Biological and Pharmaceutical Bulletin, 29, 1267-1270. http://dx.doi.org/10.1248/bpb.29.1267

[29] Chiu, P.Y., Luk, K.F., Leung, H.Y., Ng, K.M. and Ko, K.M. (2008) Schisandrin B Stereoisomers Protect against Hypoxia/Reoxygenation-Induced Apoptosis and Inhibit Associated Changes in $\mathrm{Ca}^{2+}$-Induced Mitochondrial Permeability Transition and Mitochondrial Membrane Potential in H9c2 Cardiomyocytes. Life Sciences, 82, 1092-1101. http://dx.doi.org/10.1016/j.lfs.2008.03.006

[30] Chai, H., Wang, Q., Huang, L., Xie, T. and Fu, Y. (2008) Ginsenoside Rb1 Inhibits Tumor Necrosis Factor-Alpha-Induced Vascular Cell Adhesion Molecule-1 Expression in Human Endothelial Cells. Biological and Pharmaceutical Bulletin, 31, 2050-2056. http://dx.doi.org/10.1248/bpb.31.2050

[31] Yim, T.K. and Ko, K.M. (1999) Methylenedioxy Group and Cyclooctadiene Ring as Structural Determinants of Schisandrin in Protecting against Myocardial Ischemia-Reperfusion Injury in Rats. Biochemical Pharmacology, 57, 77-81. http://dx.doi.org/10.1016/S0006-2952(98)00297-4

[32] Fong, W.F., Wan, C.K., Zhu, G.Y., Chattopadhyay, A., Dey, S., Zhao, Z., et al. (2007) Schisandrol A from Schisandra Chinensis Reverses P-Glycoprotein-Mediated Multidrug Resistance by Affecting Pgp-Substrate Complexes. Planta Medica, 73, 212-220. http://dx.doi.org/10.1055/s-2007-967120

[33] Pan, Q., Lu, Q., Zhang, K. and Hu, X. (2006) Dibenzocyclooctadiene Lingnans: A Class of Novel Inhibitors of PGlycoprotein. Cancer Chemotherapy and Pharmacology, 58, 99-106. http://dx.doi.org/10.1007/s00280-005-0133-1

[34] Ito, S., Suki, B., Kume, H., Numaguchi, Y., Ishii, M., Iwaki, M., et al. (2010) Actin Cytoskeleton Regulates StretchActivated $\mathrm{Ca}^{2+}$ Influx in Human Pulmonary Microvascular Endothelial Cells. American Journal of Respiratory Cell and Molecular Biology, 43, 26-34. http://dx.doi.org/10.1165/rcmb.2009-00730C

[35] van Kesteren, R.E. and Geraerts, W.P. (1998) Molecular Evolution of Ligand-Binding Specificity in the Vasopressin/Oxytocin Receptor Family. Annals of the New York Academy of Sciences, 839, 25-34. http://dx.doi.org/10.1111/j.1749-6632.1998.tb10728.x

[36] Rembold, C.M. (1992) Regulation of Contraction and Relaxation in Arterial Smooth Muscle. Hypertension, 20, 129137. http://dx.doi.org/10.1161/01.HYP.20.2.129

[37] Ives, S.J., Andtbacka, R.H., Kwon, S.H., Shiu, Y.T., Ruan, T., Noyes, R.D., et al. (2012) Heat and Alpha1-Adrenergic Responsiveness in Human Skeletal Muscle Feed Arteries: The Role of Nitric Oxide. Journal of Applied Physiology, 
113, 1690-1698.

[38] Striessnig, J., Pinggera, A., Kaur, G., Bock, G. and Tuluc, P. (2014) L-type Ca Channels in Heart and Brain. Wiley Interdisciplinary Reviews: Membrane Transport and Signaling, 3, 15-38. http://dx.doi.org/10.1002/wmts.102

[39] Hermsmeyer, K., Sturek, M. and Rusch, N.J. (1988) Calcium Channel Modulation by Dihydropyridines in Vascular Smooth Muscle. Annals of the New York Academy of Sciences, 522, 25-31. http://dx.doi.org/10.1111/j.1749-6632.1988.tb33339.x

[40] Connolly, M.J., Prieto-Lloret, J., Becker, S., Ward, J.P. and Aaronson, P.I. (2013) Hypoxic Pulmonary Vasoconstriction in the Absence of Pretone: Essential Role for Intracellular $\mathrm{Ca}^{2+}$ Release. The Journal of Physiology, 591, 44734498. http://dx.doi.org/10.1113/jphysiol.2013.253682

[41] Perez, C.G., Copello, J.A., Li, Y., Karko, K.L., Gomez, L., Ramos-Franco, J., et al. (2005) Ryanodine Receptor Function in Newborn Rat Heart. American Journal of Physiology-Heart and Circulatory Physiology, 288, H2527-H2540. http://dx.doi.org/10.1152/ajpheart.00188.2004

[42] Navarro-Dorado, J., Garcia-Alonso, M., van Breemen, C., Tejerina, T. and Fameli, N. (2014) Calcium Oscillations in Human Mesenteric Vascular Smooth Muscle. Biochemical and Biophysical Research Communications, 445, 84-88. http://dx.doi.org/10.1016/j.bbrc.2014.01.150

[43] Cribbs, L.L. (2006) T-Type $\mathrm{Ca}^{2+}$ Channels in Vascular Smooth Muscle: Multiple Functions. Cell Calcium, 40, 221230. http://dx.doi.org/10.1016/j.ceca.2006.04.026

[44] Jackson, W.F. (2000) Ion Channels and Vascular Tone. Hypertension, 35, 173-178.

http://dx.doi.org/10.1161/01.HYP.35.1.173 